\title{
Localization of the Growth-Associated Phosphoprotein GAP-43 $(B-50, F 1)$ in the Human Cerebral Cortex
}

\author{
Larry I. Benowitz,, ${ }^{1,4}$ Nora I. Perrone-Bizzozero, ${ }^{1}$ Seth P. Finklestein, ${ }^{2}$ and Edward D. Bird ${ }^{3}$ \\ Departments of ${ }^{1}$ Psychiatry, ${ }^{2}$ Neurology, and ${ }^{3}$ Neuropathology, and ${ }^{4}$ Program in Neuroscience, Harvard Medical School, \\ Mailman Research Center, McLean Hospital, Belmont, Massachusetts 02178
}

\begin{abstract}
The growth-associated phosphoprotein GAP-43 is a component of the presynaptic membrane that has been linked to the development and functional modulation of neuronal connections. A monospecific antibody raised against rat GAP. 43 was used here to study the distribution of the protein in cortical and subcortical areas of the human brain. On Western blots, the antibody recognized a synaptosomal plasma membrane protein that had an apparent molecular weight and isoelectric point similar to GAP-43 of other species. In brain tissue reacted with the antibody, the heaviest immunoreactivity was found in associative areas of the neocortex, particularly within layers 1 and 6 , in the molecular layer of the dentate gyrus, the caudate putamen, and the amygdala. In contrast, primary sensory or motor reglons of the cortex, portions of dorsal thalamus, and cerebellum showed only light staining. Staining was generally confined to the neuropil, which showed punctate labeling, whereas most neuronal somata and fiber bundles were unreactive. The pronounced variations in GAP-43 immunostaining among various areas of the human brain may reflect different potentials for functional and/or structural remodeling.
\end{abstract}

Functional plasticity in the mammalian brain appears to involve both pre- and post-synaptic mechanisms. In the rat hippocampus, long-lasting changes in synaptic efficacy that result from high-frequency stimulation of the perforant pathway require activation of postsynaptic $N$-methyl-D-aspartate (NMDA) glutamate receptors (Collingridge et al., 1983) and are also associated with persistent increases in the level of excitatory neurotransmitter released from presynaptic endings (Bliss et al., 1986). The presynaptic changes may involve the phosphorylation of one or more protein kinase $\mathrm{C}(\mathrm{PKC})$ substrates since manipulations of PKC with phorbol esters can either mimic, enhance, or prevent long-term potentiation (LTP) (Akers et al., 1986; Malenka et al., 1986).

Received Apr. 7, 1988; reviscd July 20, 1988; accepted July 25, 1988.

We gratefully acknowledge the support of the National Eye Institute (EY05690 to L.B.), the National Institute of Neurological, Communicative Diseases and Stroke and National Institute of Mental Health (NS25830 to L.B. and MH/NS31862 to E.D.B.), the American Heart Association (to S.P.F.), and the Hereditary Disease Foundation (to E.D.B.). We wish to thank David Weiner, Jonathan Winickoff, Paul Apostolides, and William Rodriguez for help in cutting and reacting sections, Dr. Ann McKee (Massachusetts General Hospital) for assistance in obtaining tissue, and Martha Shea for secretarial help. We also wish to acknowledge Paul Apostolides for pointing out the similarities in distributional patterns between GAP-43 and NMDA receptors in rat brain.

Correspondence should be addressed to Dr. Larry I. Benowitz, McLean Hospital, 115 Mill Street, Belmont, MA 02178.

Copyright (C) 1989 Society for Neuroscience $0270-6474 / 89 / 030990-06 \$ 02.00 / 0$
One PKC substrate that appears to play a role in synaptic plasticity is the neuron-specific, growth-associated phosphoprotein GAP-43 (F1, B-50, pp 46) (Akers and Routtenberg, 1985; Lovinger et al., 1985; Snipes et al., 1987). When neuronal connections are first being established, this protein is synthesized at high levels and transported to growth cones and immature synapses (Skene and Willard, 1981a, b; Benowitz and Lewis, 1983; Katz et al., 1985; Meiri et al., 1986; Perrone-Bizzozero et al., 1986; Skene et al., 1986). Although most neurons cease to express high levels of GAP-43 after establishing mature synaptic relationships (Skene and Willard, 1981a, b; Benowitz and Lewis, 1983; Katz et al., 1985; Jacobson et al., 1986; Meiri et al., 1986; Skene et al., 1986; Baizer and Fishman, 1987), certain subsets of nerve cells continue to express the gene (Neve et al., $1987,1988)$ and convey the protein to their presynaptic terminals (Gispen et al., 1985; Kristjansson et al., 1986; Benowitz et al., 1988; McGuire et al., 1988) throughout life. In at least one site where the protein persists in the mature CNS, the rat hippocampus, changes in its phosphorylation state have been found to correlate highly with the intensity and duration of LTP (Akers and Kouttenberg, 1985; Lovinger et al., 1985; Snipes et al., 1987). These observations have led to the suggestion that phosphorylation of GAP-43 may bc associatcd with alterations in membrane activity or structure similar to those that take place during development (Nelson and Routtenberg, 1985; Routtenberg, 1985; Jacobson et al., 1986; Pfenninger, 1986; Benowitz and Routtenberg, 1987).

In view of the possible role of GAP-43 in synaptic plasticity, we have used a monospecific antibody to identify regions of the adult human brain that contain high levels of this protein. Our results demonstrate striking regional variations in the distributional pattern of GAP-43, with high concentrations in parts of the associative neocortex and the hippocampus but low levels in primary sensory or motor areas of cortex and in much of the brain stem.

\section{Materials and Methods}

Antibodies. Antibodies against purified GAP-43 were raised in sheep as described (Neve et al., 1987; Benowitz et al., 1988). Cross-reactivity of the affinity-purified IgG fraction with human GAP-43 is described below.

Tissue. Brain tissue was dissected from 3 individuals, a 64-year-old female (postmortem interval, PMI $=9 \mathrm{hr}, \mathrm{B1042}$ ), a 56-year-old male $(\mathrm{PMI}=12.5 \mathrm{hr}, \mathrm{B} 1047)$, and a 52-year-old male (PMI $=2 \mathrm{hr}, \mathrm{B} 1154)$. All subjects were free of any known neurological defect. Tissue was obtained with familial consent under the protocols of the McLean Hospital Brain Tissue Resource Center. Cortical areas dissected included the primary somatosensory cortex (Brodmann area 1, A1), motor cortex (A4), frontal cortex (A10 and/or A11), striate cortex (A17), peristriate cortex (A18 or A19), inferior temporal cortex (A20), cingulate gyrus (A24), parahippocampal gyrus (A28), supramarginal gyrus (A40), inferior precentral region (A44), and hippocampal region; also included 
were the caudate putamen, amygdala, dorsal thalamus, hypothalamus, and cerebellum. Tissue blocks, with volumes of approximately $0.5-1$ $\mathrm{cm}^{3}$, were immersion-fixed in $4 \%$ paraformaldehyde buffered with 0.1 M phosphate, $\mathrm{pH} 7.4$ (PBS), at $0^{\circ} \mathrm{C}$ overnight, cryoprotected with buffered $30 \%$ sucrose $\left(0^{\circ} \mathrm{C}\right.$ for $\left.2 \mathrm{~d}\right)$, and stored at $-70^{\circ} \mathrm{C}$ prior to sectioning. Unfixed tissue was also taken from several cortical regions and frozen immediately to $-70^{\circ} \mathrm{C}$ for gel electrophoretic analysis of proteins.

Immunocytochemistry. Sections were cut at $40 \mu \mathrm{m}$ intervals on the freezing stage of a sliding microtome $(n=2)$ or on a cryostat $\left(-23^{\circ} \mathrm{C}\right)$ and stored for up to 2 weeks in PBS containing $0.1 \% \mathrm{NaN}_{3}$. Cortical sections were taken to include all laminae plus some underlying white matter. In the principal series to be analyzed, sections from all brain regions were processed together in the same $50 \mathrm{ml}$ tubes. Free-floating sections were reacted for $30 \mathrm{~min}$ in $\mathrm{CH}_{3} \mathrm{OH}$ containing $1 \% \mathrm{H}_{2} \mathrm{O}_{2}$ to inhibit endogenous peroxidase activity, washed $3 \times$ in PBS, blocked with $20 \%$ normal rabbit serum (NRS) $30 \mathrm{~min}$, and then incubated for 1-2 d with either neutral sheep serum, 1/2000, as a control, or sheep anti-GAP-43 serum (affinity-purified IgG fraction) at $1 / 2000$. Sections were rinsed 3 times, including once overnight, in PBS containing excess NRS $(10 \%), \mathrm{NaCl}(1.8 \%)$, and Triton X-100 $(0.7 \%)$ in order to optimize elution of nonspecifically bound primary antibodies. Sections were then incubated with a biotinylated secondary antibody to sheep IgG made in rabbit $(1 / 250,1 \mathrm{hr}$, washed $3 \times$ in PBS $(+2 \%$ BSA, $0.3 \%$ Triton $\mathrm{X}-100,1 \% \mathrm{NRS})$, and then reacted with avidin-biotin complex conjugated to HRP according to the manufacturer's specifications (Vector Labs, Burlingame, CA). HRP was visualized using 0.5\% diaminobenzidine and $0.01 \% \mathrm{H}_{2} \mathrm{O}_{2}$ in $50 \mathrm{~mm}$ Tris- $\mathrm{HCl}(\mathrm{pH} 7.5)$ for $5 \mathrm{~min}$. Sections were mounted onto chrom-alum-subbed slides, dehydrated, and covered.

Two-dimensional gel electrophoresis of synaptosomal plasma membrane proteins. Direct comparison of GAP-43 levels in different brain regions was achieved by examining the proteins present in synaptosomal plasma membrane (SPM) fractions by 2-dimensional gel electrophoresis. Starting with unfixed, freshly dissected segments of cortical tissue, $0.2-0.4 \mathrm{~cm}^{3}$, containing all 6 cortical layers but minimizing the amount of white matter, SPM fractions were prepared using a slight modification of the protocol of Whitaker and Greengard (1971). Tissue was homogenized in $0.32 \mathrm{M}$ sucrose buffered to $\mathrm{pH} 7.4$ with $0.1 \mathrm{M}$ Tris containing $5 \mathrm{~mm}$ EGTA, $5 \mathrm{~mm} \mathrm{MgCl}_{2}$, aprotinin, and leupeptin $\left(0^{\circ} \mathrm{C}\right)$. The homogenate was centrifuged at $1000 \times g 10 \mathrm{~min}$, the supernatant recentrifuged at $17,000 \times g$ for $30 \mathrm{~min}$, the P2 pellet lysed in hypotonic buffer (with trituration), and the lysate layered onto a discontinuous sucrose gradient. Material collected after a $54,000 \times g 2 \mathrm{hr}$ centrifugation at the $0.6 / 1.2 \mathrm{M}$ sucrose interface was diluted, recentrifuged, resuspended in $10 \mathrm{~mm}$ Tris, pH 7.4/5 mM EGTA/5 mM $\mathrm{MgCl}_{2}$, and the amount of protein determined by the method of Lowry (Lees and Paxman, 1972). SPM protein, $100 \mu \mathrm{g}$, from each of 5 cortical areas was separated on isoelectric focusing gels (pH 4.1-6.8), then separated in the second dimension on $5-15 \%$ linear gradient SDS-polyacrylamide gels (Benowitz and Lewis, 1983). Proteins were visualized using the reduced silver staining method (Oakley et al., 1980).

Western blots. An SPM fraction was prepared from freshly dissected cortical tissue and the proteins separated by 2-dimensional gel electrophoresis as above. Proteins were transferred electrophoretically from the 2-D gel to nitrocellulose membrane $(0.22 \mu \mathrm{m}, 250 \mathrm{~mA}, 15 \mathrm{hr})$ with $0.1 \%$ SDS present in the transfer buffer (Meiri et al., 1986). Blots were incubated with an excess of rabbit serum to block nonspecific binding of IgGs, then reacted with sheep anti-GAP-43 IgG at a $1 / 1000$ dilution. Binding of the primary antibody was visualized using a rabbit antibody to shcep IgG conjugated to HRP and 4-chloronaphthol as a chromagen. To verify further that the antibody did not cross-react with any other proteins not visualized on the 2-D gel transfers, $75-100 \mu \mathrm{g}$ of total brain protein and SPM protein were separated on 1-D SDS polyacrylamide gels, transferred electrophoretically, and probed with either the antiGAP-43 IgG fraction or neutral sheep serum at similar concentrations $(1 / 2000)$.

\section{Results}

As shown in Figure $1 a$, the anti-GAP-43 antibody reacted with a protein in the SPM fraction from human cortex that had an apparent molecular weight $(\sim 51 \mathrm{kDa})$ and isoelectric point ( $\sim 4.7$ ) similar to GAP-43 of other species (Jacobson et al., 1986; Meiri et al., 1986; Perrone-Bizzozero et al., 1986). The slightly higher molecular size of the human protein relative to GAP -43 of rodents is at least partially explained by the primary sequence data (Kosik et al., 1988; Ng et al., 1988). On 1-D gel Western blots of total brain protein or SPM fraction, this 51 $\mathrm{kDa}$ protein was the only band recognized by the antibody (data not shown). In brain tissue reacted with the anti-GAP-43 IgG, a granular pattern of staining was seen in the neuropil (Fig. 1b), which varied greatly in intensity between different regions and laminae (Fig. 1c). Most cell bodies and fiber tracts were unreactive, although stained somata were occasionally observed in some regions (Fig. 1c). In cortex, these were usually deeplying pyramidal cells. Case B 1 154, however, showed no cellular staining anywhere. Conceivably, the presence of positively staining somata in some cases but not others may parallel the aging-related accumulations of the protein visualized in the aging rat brain (Oestreicher et al., 1987). Control sections reacted with preimmune whole sheep serum instead of the affinity-purified anti-GAP-43 IgG showed no immunostaining at all (Fig. 1d). As another control, parallel experiments carried out in the rat showed that preabsorption of the anti-GAP-43 antibody with a 100-fold excess of purified GAP-43 eliminated almost all immunoreactivity (Benowitz et al., 1988).

In the cerebral cortex, the intensity of GAP-43 immunostaining was gencrally low in primary sensory and motor arcas, but quite intense in associative regions. As shown in the top row of Figure 2, staining was low in primary somatosensory cortex $(a)$, somewhat higher, but still quite modest, in striate cortex $(b)$, and low in motor cortex $(c)$. Within the sensory areas, the highest levels of staining were generally seen in layer 1, layer 6 , or both. Associative areas of the cerebral cortex, several of which are represented in the middle row of Figure 2, showed considerably denser staining. Staining in these areas sometimes included laminae other than 1 and 6 , as in the cingulate cortex (Fig. 2d) and supramarginal gyrus (A40, Fig. 2f), or was extremely dense in layer 6 , as in the inferior temporal cortex (Area 20 , Fig. 2e). The hippocampal region showed heavy staining in the molecular layer (Mol, Fig. $2 g$ ) of the dentate gyrus, and modest staining in the stratum lacunosum moleculare (LMol) of the CAl field. The caudate putamen showed intense immunoreactivity in the neuropil but none in the perforating white matter (Fig. $2 h$ ). Dense staining was likewise found in the amygdala and in portions of the medial hypothalamus (not shown). The cerebellum (Fig. 2i) and a portion of the thalamus sampled (not shown) showed only light staining. The other 2 brains studied showed regional variations similar to those shown in Figure 2 (B1047).

To confirm that the regional differences in GAP-43 immunostaining accurately reflected variations in the levels of the protein, synaptosomal plasma membranes from several cortical areas were analyzed by 2-D gel electrophoresis. As shown in Figure 3, the inferior temporal cortex (Area 20) showed high concentrations of GAP-43, whereas the striate cortex (Area 17) showed very little. Low levels were also seen in SPM from peristriate cortex (A18) and motor cortex (A4), while the orbitofrontal cortex (A11) showed intermediate levels (not shown). Unlike GAP-43, most other SPM proteins seemed to be present at similar levels in different regions (Fig. 3).

\section{Discussion}

These results demonstrate striking regional variations in the distribution of GAP-43 in the human brain. Of particular interest are the pronounced differences between primary sensory 

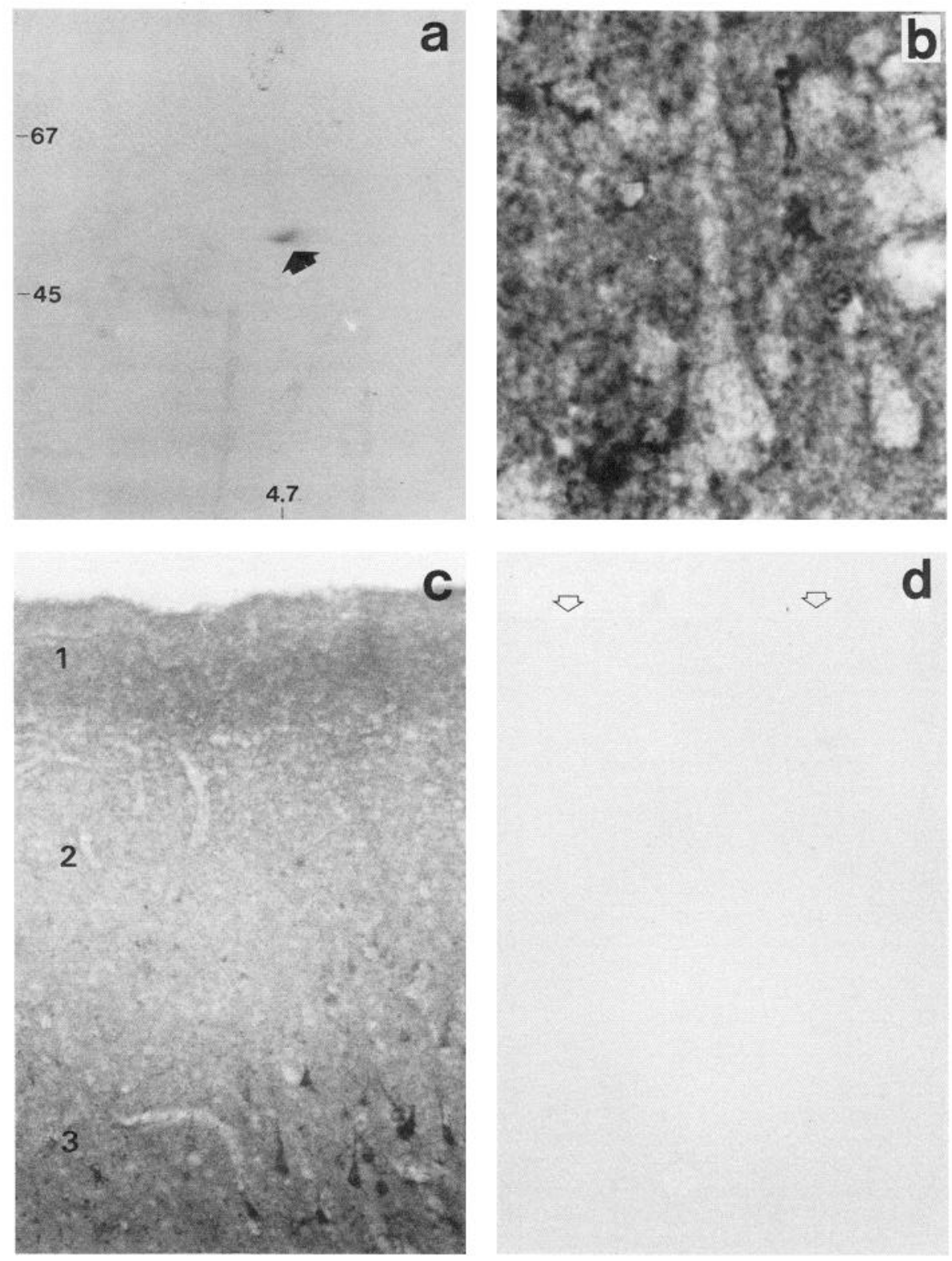

Figure 1. GAP-43 in the human brain. $a$, The synaptosomal plasma membrane fraction from the cortex includes a highly acidic protein, $M_{r}=51 \mathrm{kDa}$, which cross-reacts on Western blots with an antibody made in sheep against rat GAP-43 (arrow). Apparent molecular weights (in kilodaltons) are indicated on the abscissa, and the isoelectric point of GAP-43 is on the ordinate. $b$, Immunohistochemical localization of GAP-43 in the inferior temporal cortex. Note punctate staining in neuropil and absence of staining in pyramidal cell bodies. $c$, Immunostaining for GAP43 in striate cortex. Note lamination and occasional stained somata in layer 3. $d$, Control section from identical region of striate cortex stained with neutral sheep serum $(1 / 2000)$ substituted for immune serum. Open arrows point to faint outline of section (photo printed at twice the density of $c$ ).

and motor areas, on the one hand, which showed low levels of GAP-43, and certain associative cortical regions and the hippocampus, which showed dense immunostaining. High levels of GAP-43 were also seen in certain subcortical structures, including the caudate putamen, amygdala, and medial hypothalamus, whereas the cerebellum and one region of dorsal thalamus sampled showed only low levels.

At the cortical level, several major differences are apparent between the distributional patterns of GAP-43 in rat and man. As recently described (Benowitz et al., 1988), the rat cortex shows a laminar distribution of GAP-43 that is qualitatively similar to that found here, as well as some overall variations in immunostaining across cytoarchitectonic areas. However, these are not nearly as striking as the present findings in the human cortex, where staining density varies from very faint in parts of somatosensory or motor cortex, to extremely dense in certain associative areas (e.g., frontal, inferior temporal, temporoparietal regions). These differences are likely to reflect a greater regional specialization in the human cortex for associative functions. Another interspecific difference is that, whereas

Figure 2. Regional variations in GAP-43 immunoreactivity. Primary sensory and motor areas of cortex are shown in top row: a, primary somatosensory cortex (A1); $b$, visual (striate) cortex (A17); $c$, motor cortex (A4). Associative areas are shown in middle row: $d$, cingulate cortex (A24); $e$, inferior temporal region (A20); $f$, supramarginal gyrus of the temporoparietal region (A40). Bottom row: $g$, the hippocampal region; $h$, caudate putamen; and $i$, cerebellum. $1-6$ refer to cortical layers 1-6; CA1, Ammon's horn, field 1; $M o l$, molecular layer; $G C$, granule cells; $L M o l$, stratum lacunosum moleculare; Hil, hilus. Arrow in $e$ indicates a reproducible discontinuity in layer VI staining that may correspond to a cytoarchitectonic boundary within Area 20. 

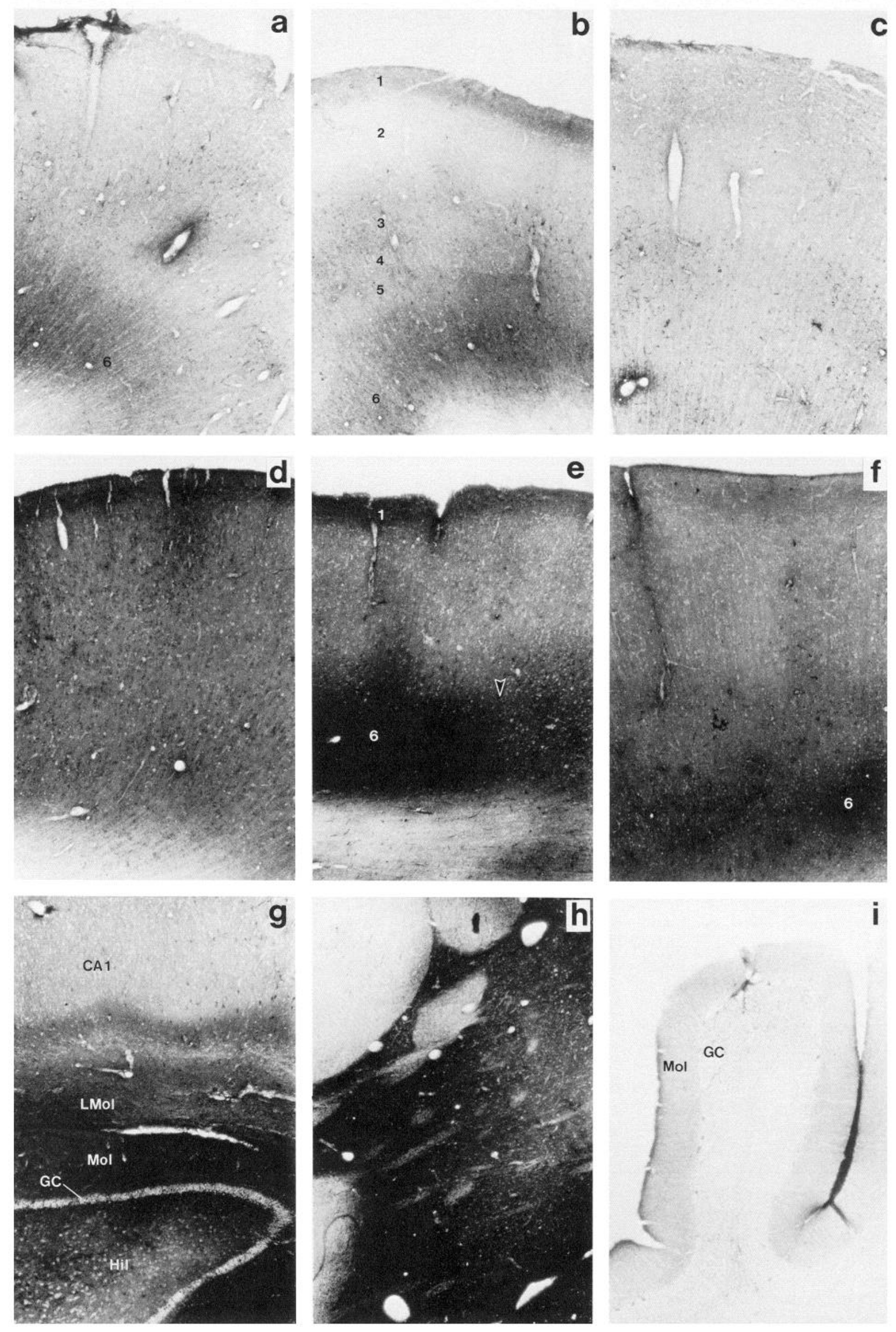

i

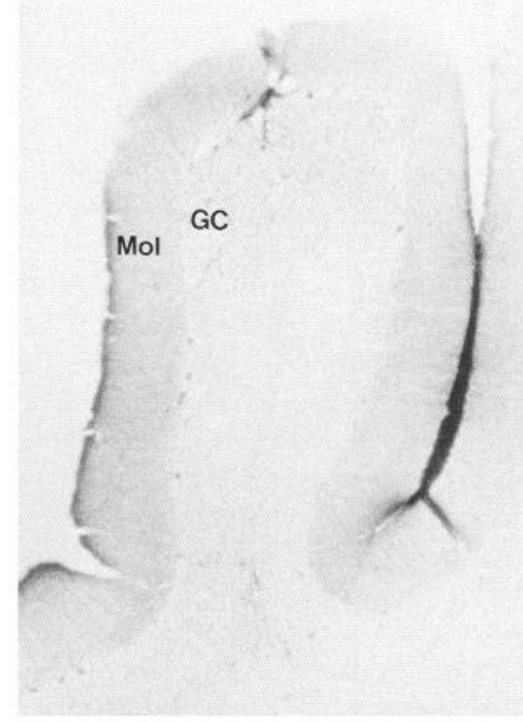


Figure 3. Synaptosomal plasma membrane proteins from the striate cortex (Area 17) and inferior temporal cortex (Area 20). Proteins were separated by 2 -dimensional gel electrophoresis and stained with the reduced silver method as described in the text. Arrow points to GAP-43, recognized by its electrophoretic migration position on the Western blot (Fig. 1a).
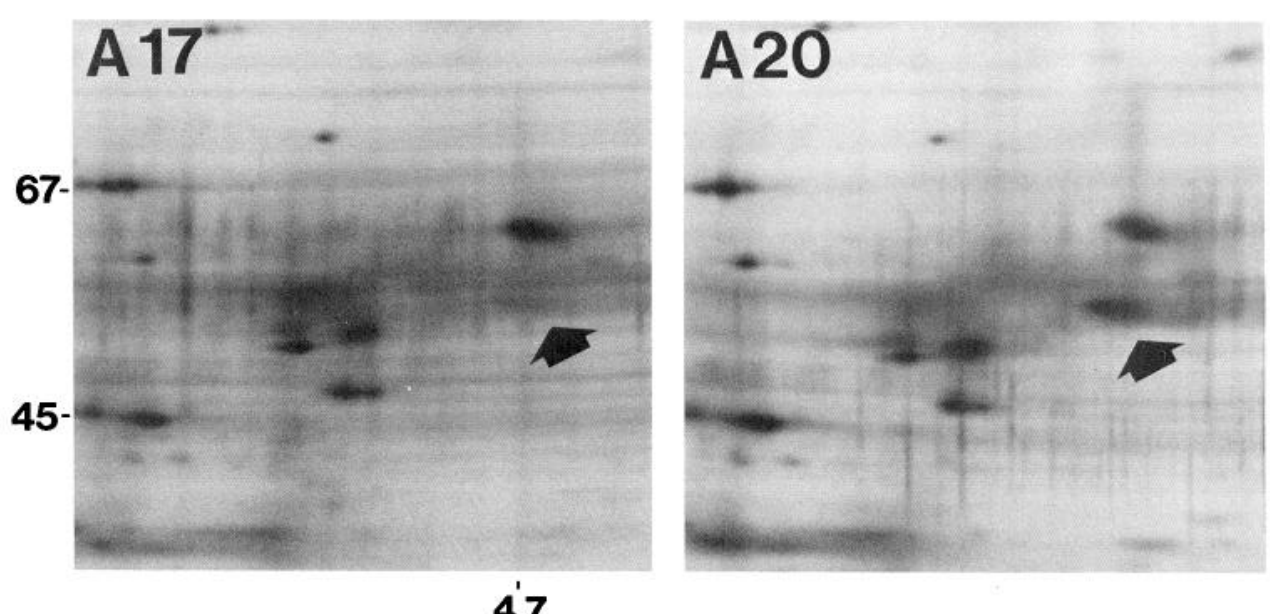

4.7 immunostaining in the rat dentate gyrus is restricted to the inner third of the molecular layer, the whole width of this layer is darkly stained in the human dentate. In addition, the dendritic fields of the human hippocampal CA1 region show a moderately dark staining but are lighter than the dentate, while the rat shows the opposite pattern. Below the level of the cerebral cortex, however, the distribution of GAP-43 in the human brain appears to resemble that found in rat (Benowitz et al., 1988). In the rat, high levels of GAP-43 were found in a continuum of subcortical structures that included the anterior olfactory nucleus, olfactory tubercle, caudate putamen, nucleus accumbens, amygdala, bed nucleus of the stria terminalis, preoptic area, and medial hypothalamus, and the few subcortical areas sampled from human brain showed the same pattern. In contrast, staining was not seen in the rat brain in cerebellum or in ascending relay nuclei of sensory-specific information or in motor areas. It has been proposed that these latter areas may have synaptic relationships that become relatively "hard-wired" at some early point in development (Benowitz et al., 1988).

In the rhesus monkey, Nelson et al. (1987) reported marked variations in GAP-43 (F1) phosphorylation in different visual processing areas of the cortex, with low levels in striate and extrastriate cortex and considerably higher levels in the inferior temporal region (see Benowitz and Routtenberg, 1987, and Snipes et al., 1987, for the equivalence of GAP-43 and protein F1). This finding had suggested that in the visual system, the protein may be associated primarily with integrative areas that are putative sites of information storage. Although it could not be concluded whether those regional differences reflected variations in levels of the protein per se (rather than, for example, levels of the kinase, cofactors, or phosphatase), the present studies indicate that they are likely to represent variations in the concentrations of GAP-43 itself similar to the general pattern found here in the human cortex. Hence, marked regional variations in GAP-43 levels between associative and primary sensory or motor areas of the cortex are likely to be a conserved, general feature of the primate brain.

With regard to the cells that give rise to the GAP-43-rich terminals, the use of radiolabeled cDNA probes to the human GAP-43 gene has revealed highest concentrations of GAP-43 mRNA in the same associative cortical areas that were found here to contain high levels of the protein (Neve et al., 1987, 1988). Thus, the regional variations observed in the present study are likely to be regulated at the level of gene transcription. By in situ hybridization, cortical neurons with highest levels of GAP-43 mRNA were localized in layer 2 (Neve et al., 1988) and appear to coincide with the small pyramidal cells that give rise tolocal intracortical associations(Szenthagothai, 1979; Lund et al., 1985). In the hippocampus, pyramidal cells in the CA1 and CA 3 fields were also seen by in situ hybridization to express appreciable levels of the mRNA. Hence, the GAP-43-rich nerve terminals of the cortex and hippocampus seem primarily to represent presynaptic endings of locally projecting pyramidal cells. The source of GAP-43 in most subcortical areas has not yet been established, although in at least one subcortical area, the caudate putamen, it is also likely to arise from cortical neurons, since GAP-43 mRNA levels are low in the neurons of the caudate putamen itself (Neve et al., 1987, 1988).

In the rat brain, the distribution of GAP-43 in many respects parallels the distribution of several molecules that have been implicated in the postsynaptic triggering of LTP, including the NMDA receptor and $\mathrm{Ca}^{2+}$-calmodulin (Ca-CM) kinase II. Like GAP-43, these molecules are particularly abundant in layer 1 of cortex, the caudate putamen, and the CAl field of the hippocampus, while being present at considerably lower levels in most of the brain stem (Ouimet et al., 1984; Monaghan and Cotman, 1985; Benowitz et al., 1988). However, some differences exist, e.g., in the preoptic area and hypothalamus, where GAP-43 levels are relatively high but Ca-CM kinase and NMDA receptors are low (Ouimet et al., 1984; Monaghan and Cotman, 1985; Benowitz et al., 1988). Despite these differences, parallels that do exist suggest the intriguing possibility that presynaptic changes in the phosphorylation of GAP-43 may function as part of a transsynaptic mechanism which also requires postsynaptic activation of the NMDA receptor and Ca-CM kinase II (Linden et al., 1987). Whether the parallel distribution of GAP-43, Ca$\mathrm{CM}$ kinase II, and NMDA receptors likewise occurs in the human brain remains to be established. In any case, the striking association of GAP-43 levels with synaptic development, together with the correlation between GAP-43 (F1) phosphorylation and synaptic plasticity, suggest that the GAP-43-positive synapses visualized here may be capable of undergoing functional or even structural remodeling in response to physiological activity patterns. If this were the case, our results would imply that certain portions of the adult human brain, including the associative neocortex and hippocampus, may retain more of a 
capacity for synaptic remodeling than the primary sensory cortices, motor cortex, or much of the brain stem.

\section{References}

Akers, R. F., and A. Routtenberg (1985) Protein kinase C phosphorylates a $47 \mathrm{Mr}$ protein $(\mathrm{F} 1)$ directly related to synaptic plasticity. Brain Res. 334: 147-151.

Akers, R. F., D. M. Lovinger, P. A. Colley, D. J. Linden, and A. Routtenberg (1986) Translocation of protein kinase C activity may mediate hippocampal long-term potentiation. Science 231: 587-589.

Baizer, L., and M. C. Fishman (1987) Recognition of specific targets by cultured dorsal root ganglion neurons. J. Neurosci. 7: 2305-2311.

Benowitz, L. I., and E. R. Lewis (1983) Increased transport of 4449,000 dalton acidic proteins during regeneration of the goldfish optic nerve: A 2-dimensional gel analysis. J. Neurosci. 3: 2153-2163.

Benowitz, L. I., and A. Routtenberg (1987) A membrane phosphoprotein associated with neural development, axonal regeneration, phospholipid metabolism, and synaptic plasticity. Trends Neurosci. 10: $527-532$.

Benowitz, L. I., P. J. Apostolides, N. I. Perrone-Bizzozero, S. P. Finklestein, and H. Zwiers (1988) Anatomical distribution of the growthassociated protein GAP-43/B50 in the adult rat brain. J. Neurosci. 8: 339-352.

Bliss, T. V. P., R. M. Douglas, M. L. Errington, and M. A. Lynch (1986) Correlation between long-term potentiation and release of endogenous amino acids from dentate gyrus of anesthetized rats. J. Physiol. (Lond.) 377: 391-408.

Collingridge, G. L., S. J. Kchl, and H. McLennan (1983) Excitatory amino acids in synaptic transmission in the Schaffer collateral-commissural pathway of the rat hippocampus. J. Physiol. (Lond.) 334 : 33-46.

Gispen, W. H., J. L. M. Leunissen, A. B. Oestreicher, A. J. Verkleij, and $H$. Zwiers (1985) Presynaptic localization of B-50 phosphoprotein: The ACTH-sensitive protein kinase C substrate involved in rat brain phosphoinositide metabolism. Brain Res. 328: 381-385.

Jacobson, R. D., I. Virag, and J. H. P. Skene (1986) A protein associated with axon growth, GAP-43, is widely distributed and developmentally regulated in rat CNS. J. Neurosci. 6: 1843-1855.

Katz, F., L. Ellis, and K. H. Pfenninger (1985) Nerve growth cones isolated from fetal rat brain. III. Calcium-dependent protein phosphorylation. J. Neurosci. 5: 1402-1411.

Kosik, K. S., L. D. Orecchio, G. A. P. Bruns, L. I. Benowitz, G. P. MacDonald, D. R. Cox, and R. L. Neve (1988) Human GAP-43: Its deduced amino acid sequence and chromosomal localization in mouse and human. Neuron 1: 127-132.

Kristjansson, G. I., H. Zwiers, A. B. Oestreicher, and W. H. Gispen (1986) Evidence that the synaptic phosphoprotein B-50 is localized exclusively in nerve tissue. J. Neurochem. 3: 371-378.

Lees, M. B. and S. Paxman (1972) Modification of the Lowry procedure for the analysis of proteolipid protein. Anal. Biochem. 47: 184-192.

Linden, D. J., F.-S. Sheu, and A. Routtenberg (1987) DL-Aminophosphovalerate (APV) blockade of hippocampal long-term potentiation (LTP) prevents an LTP-associated increase in protein F1 phosphorylation. Soc. Neurosci. Abstr. 13: 1232.

Lovinger, D. M., R. F. Akers, R. B. Nelson, C. A. Barnes, B. L. McNaughton, and A. Routtenberg (1985) A selective increase in phosphorylation of protein F1, a protein kinase C substrate, directly related to three day growth of long term synaptic enhancement. Brain Res. 343: 137-143.

Lund, J., D. Fitzpatrick, and D. L. Humphrey (1985) Cerebral Cortex, Vol. 3, A. Peters and E. G. Jones, eds., pp. 157-205, Plenum, New York.

Malenka, R. C., D. V. Madison, and R. A. Nicoll (1986) Potentiation of synaptic transmission in the hippocampus by phorbol esters. Nature 321: 175-177.

McGuire, C. B., G. J. Snipes, and J. J. Norden (1988) Light-micro- scopic immunolocalization of the growth and plasticity-associated protein GAP-43 in the developing rat brain. Dev. Brain Res. 41:277291.

Meiri, K., K. H. Pfenninger, and M. Willard (1986) Growth-associated protein, GAP-43, a polypeptide that is induced when neurons extend axons, is a component of growth cones and corresponds to pp46, a major polypeptide of a subcellular fraction enriched in growth cones. Proc. Natl. Acad. Sci. USA 83: 3537-3541.

Monaghan, D. T., and C. W. Cotman (1985) Distribution of N-methyl D-aspartate-sensitive L- $\left[{ }^{3} \mathrm{H}\right]$-glutamate binding sites in rat brain. J. Neurosci. 6: 2909-2919.

Nelson, R. B., and A. Routtenberg (1985) Characterization of protein F1 (47 kDa, $4.5 \mathrm{pI})$ : A kinase C substrate directly related to neural plasticity. Exp. Neurol. 89: 213-224.

Nelson, R. B., D. P. Friedman, J. B. O'Neill, M. Mishkin, and A. Routtenberg (1987) Gradients of protein kinase $C$ phosphorylation in primate visual system peak in visual memory storage areas. Brain Res. 416: 387-392.

Neve, R. L., N. I. Perrone-Bizzozero, S. P. Finklestein, H. Zwiers, E. Bird, D. M. Kurnit, and L. I. Benowitz (1987) The neuronal growthassociated protein GAP-43 (B-50, Fl): Use of cDNAs to show the neuronal specificity, developmental regulation and regional distribution of the human and rat mRNAs. Mol. Brain Res. 2: 177-183.

Neve, R. L., E. Finch, E. D. Bird, and L. I. Benowitz (1988) Growthassociated protein GAP-43 is expressed selectively in associative regions of the adult human brain. Proc. Natl. Acad. Sci. USA 85: 36383642.

Ng, S.-C., S. M. de la Monte, G. L. Conboy, L. R. Karns, and M. C. Fishman (1988) Cloning of human GAP-43: Growth association and ischemic resurgence. Neuron $1: 133-139$.

Oakley, B. R., D. R. Kirsch, and N. R. Morris (1980) A simplified ultrasensitive silver stain for detecting proteins in polyacrylanide gels. Anal. Biochem. 105: 361-363.

Oestreicher, A. B., L. V. Dekker, R. J. Bloemen, S. Keur, L. H. Schrama, and W. H. Gispen (1987) The neuron-specific phosphoprotein B-50: Age-dependent changes in distribution in the rat brain. J. Neurochem. (Suppl.) 48: $\mathrm{S} 155$.

Ouimet, C. C., T. L. McGuinness, and P. Greengard (1984) Immunocytochemical distribution of calcium/calmodulin-dependent protein kinase II in rat brain. Proc. Natl. Acad. Sci. USA 81: 5604-5608.

Perrone-Bizzozero, N. I., S. P. Finklestein, and L. I. Benowitz (1986) Synthesis of a growth-associated protein by embryonic rat cerebrocortical neurons in vitro. J. Neurosci. 6: 3721-3730.

Pfenninger, K. H. (1986) Of nerve growth cones, leukocytes and memory: Second messenger systems and growth-regulated proteins. Trends Neurosci. 9: 562-565.

Routtenberg, A. (1985) Phosphoprotein regulation of memory formation: Enhancement and control of synaptic plasticity by protein kinase C and protein F1. Ann. NY Acad. Sci. 444: 203-211.

Skene, J. H. P., and M. Willard (1981a) Changes in axonally transported proteins during axon regeneration in toad retinal ganglion cells. J. Cell Biol. 89: 86-95.

Skene, J. H. P., and M. Willard (1981b) Axonally transported proteins associated with growth in rabbit central and peripheral nervous system. J. Cell Biol. 89: 96-103.

Skene, J. H. P., R. D. Jacobson, G. J. Snipes, C. B. McGuire, J. J. Norden, and J. A. Freeman (1986) A protein induced during nerve growth (GAP-43) is a major component of growth cone membranes. Science 233: 783-786.

Snipes, G. J., S. Y. Chan, C. B. McGuire, B. R. Costello, J. J. Norden, J. A. Freeman, and A. Routtenberg (1987) Evidence for the coidentification of GAP-43, a growth-associated protein, and F1, a plasticity-associated protein. J. Neurosci. 7: 4066-4075.

Szenthagothai, J. (1979) The Neurosciences: Fourth Study Program, F. O. Schmitt and F. G. Worden, eds., pp. 399-415, MIT Press, Cambridge, MA.

Whitaker, V. P., and P. Greengard (1971) The isolation of synaptosomes from the brain of a teleost fish. J. Neurochem. 18: 173-176. 